\title{
Comparison of Serum and Salivary Neopterin with Troponin-I and CK-MB Levels in Acute Coronary Syndrome
}

\author{
Rama K Reddy $\mathrm{YV}^{1}$, Srilakshmi $\mathrm{P}^{2}$, KM Cherian ${ }^{3}$, Sai Babu ${ }^{4}$
}

\begin{abstract}
Objective: To determine the levels of serum and salivary neopterin in acute coronary syndrome (ACS) in comparison with established biomarkers like Troponin-I and CK-MB.

Background: Neopterin is the product of activated macrophage which is released by activated monocyte by cytokines during the acute phase response of ACS, can be used as a biomarker for diagnosis of ACS.

Materials and methods: ACS $(n=675)$ individuals with or without ST-segment elevation myocardial infarction were enrolled for the study, for three years. Serum and saliva neopterin were estimating by HPLC and compared with established biomarkers like Troponin-I and CK-MB.

Results: Increased serum and salivary neopterin levels were observed in patients with STEMI, NSTEMI, and UA of ACS. From the ROC analysis serum and salivary neopterin were found to be more sensitive and specific than the established biomarkers of ACS like Troponin-I and CK-MB, in diagnosing ACS. Conclusion: Neopterin being more sensitive and specific than troponin and CK-MB, can be a marker of ACS. The collection of saliva being Noninvasive salivary neopterin can be easily estimated than serum neopterin.
\end{abstract}

Keywords: Acute coronary syndrome, High-performance liquid chromatography, Noninvasive, Salivary neopterin, Salimetrics oral swab. Indian Journal of Medical Biochemistry (2019): 10.5005/jp-journals-10054-0089

\section{INTRODUCTION}

A cute coronary syndrome (ACS) being a life-threatening disorder that remains a source of high morbidity and mortality despite advances in treatment. Approximately $80 \%$ of these comprise either unstable angina (UA) or non-ST-segment elevation myocardial infarction (NSTEMI), and 20\% were ST-segment elevation myocardial infarction (STEMI). ${ }^{1,2}$ Although clinical presentation and ECG are important components in diagnosis and management of the ACS, as well as biochemical markers play a fundamental role in monitoring risk stratification, and therapeutic management. ${ }^{3,4}$

Inflammation and macrophage activation play a central role in atherogenesis and plaque liability in patients with ACS. ${ }^{4,5}$ Unstable atherosclerotic plaques which holds activated $T$ cells, produces cytokine, interferon- $\gamma$ (IFN- $\gamma)$, which activate macrophages and interferes with plaque matrix collagen synthesis, which causes disruption of atherosclerotic plaque and leads to intracoronary thrombus formation, which leads to the ACS. ${ }^{6}$ Plaque disruption occurs commonly where the fibrous cap is thin and profoundly where foam cells infiltrate is present. ${ }^{7}$

Neopterin is regarded as an early biomarker of the cellular immune response. It is a low-molecular compound belongs to the class of pteridines, which is produced by the activated macrophages and antigen presenting cell by stimulation with INF- $\gamma .{ }^{8}$ Increased neopterin in body fluids are associated with diseases such as malignancies, heart failure, and coronary artery disease. 9,10

Until now there are no studies in comparison of serum and salivary neopterin levels and salivary neopterin levels alone. We, therefore, compared the neopterin levels in ACS with the established biomarkers like troponin I, creatine kinase-MB (CK-MB).

\section{Materials AND MEthods}

The study was carried in patients admitted into the coronary care unit at Frontier Lifeline Hospital and Dr KM Cherian Heart Foundation, Chennai, Tamil Nadu, India, for three years. The study included 675 subjects, grouped (using ECG and chest pain), STEMI group
${ }^{1}$ Assistant Professor, ${ }^{2}$ Associate Professor, ${ }^{3}$ Chairman, ${ }^{4}$ Lab Incharge

${ }^{1.2}$ Department of Biochemistry, Mamata Medical College, Khammam, Telangana, India

${ }^{3,4}$ Department of Biochemistry, Frontier Lifeline Hospital and Dr KM Cherian's Heart Foundation, Mogappair, Chennai, Tamil Nadu, India

Corresponding Author: Rama K Reddy YV, Assistant Professor, Department of Biochemistry, Mamata Medical College, Khammam, Telangana, India, Phone: +919705246818, e-mail: krishna262424@ gmail.com

How to cite this article: Reddy RKYV, Srilakshmi $\mathrm{P}$, Cherian KM, Babu S. Comparison of Serum and Salivary Neopterin with Troponin-I and CK-MB Levels in Acute Coronary Syndrome. Indian J Med Biochem 2019;23(1):217-220.

Source of support: Nil

Conflict of interest: None

$(\mathrm{n}=135)$ and NSTEMI group $(\mathrm{n}=135)$, Unstable angina group $(n=135)$, Noncardiac chest pain group $(n=135)$ and normal controls ( $n=135$ ) who came for master health checkup. The study protocol was approved by the institutional ethical committee. After obtaining informed written and signed consent form the subjects were included in the study.

Patients with a malignant tumor, rheumatoid arthritis, renal failure, cirrhosis of the liver, heart failure, brain ischemia, and pregnant women were excluded from the study. Saliva is collected by using salimetrics oral swab. The serum and samples were stored at $-20^{\circ} \mathrm{C}$ until analysis. Routine investigations were done by using fully automated autoanalyzer (Randox RX Daytona), whereas troponin-I is estimated using Axsym Analyser.

Serum neopterin were estimated by mixing, $200 \mu \mathrm{L}$ of ethanol to $100 \mu \mathrm{l}$ of serum, to precipitate protein the mixture was centrifuged at 10,600 rpm for $10 \mathrm{~min}$ at $4^{\circ} \mathrm{C}$ to collect the supernatant; whereas for saliva neopterin, equal amounts of $(100 \mu \mathrm{L})$ ethanol and saliva were mixed and centrifuged for $10 \mathrm{~min}$ at $10,600 \mathrm{rpm}$ at $4^{\circ} \mathrm{C}$ to obtain clear saliva. Neopterin present in the saliva and serum supernatant

(O) The Author(s). 2019 Open Access This article is distributed under the terms of the Creative Commons Attribution 4.0 International License (https://creativecommons. org/licenses/by-nc/4.0/), which permits unrestricted use, distribution, and non-commercial reproduction in any medium, provided you give appropriate credit to the original author(s) and the source, provide a link to the Creative Commons license, and indicate if changes were made. The Creative Commons Public Domain Dedication waiver (http://creativecommons.org/publicdomain/zero/1.0/) applies to the data made available in this article, unless otherwise stated. 
$(20 \mu \mathrm{L})$ was used in estimating by using HPLC (Shimadzu) with LC-20 AD pump system, equipped with RF-10 AXL fluorescence detector. Separations were carried out at room temperature with a $5 \mathrm{~mm}$ reverse-phase HPLC (Phenomenex C18 column $4.6 \times 250 \mathrm{~mm}$ ). The flow rate is maintained at $1.5 \mathrm{~mL} / \mathrm{min}$ with water: acetonitrile (99:1 $\mathrm{v} / \mathrm{v})$ as the mobile phase, and the fluorescence detector was set at $353 \mathrm{~nm}$ of excitation and $438 \mathrm{~nm}$ of emission for detection. The retention time for the neopterin was $2.7 \mathrm{~min} .{ }^{11}$ Statistical analysis was done using SPSS Software-17.0.

\section{Results}

In our study, we analyzed for the risk factors such as diabetes, hypertension, familial history of CAD, smoking and food habits for ACS and found to be significant (Table 1). Basic clinical parameters like glucose, LDL-C, HDL-C were found to be significant with all the groups whereas serum creatinine found to be significant with group-III, cholesterol with group-II, triglycerides with group-IV, V and BMI, urea, total protein is found to be non-significant (Table 2).

The biomarkers for the ACS like, troponin-I, CK-MB were found to be significant with groups IV and $\mathrm{V}$ whereas serum and salivary neopterin levels were significant with groups III, IV and V (Table 3). ROC analysis of troponin, CK-MB, serum and salivary neopterin has shown greater area under the curve, with $0.771,0.745,0.885$ and 0.891 respectively, with cutoff values of $0.02(\mathrm{ng} / \mathrm{mL}), 25(\mathrm{U} / \mathrm{L})$, $8.8(\mathrm{nmol} / \mathrm{L})$, and $5.6(\mathrm{nmol} / \mathrm{L})$, respectively, which considered to be very significant biomarkers of ACS (Table 4).

\section{Discussion}

In our study raise in both serum and saliva neopterin levels in UA, both STEMI and NSTEMI groups and the ROC analysis with high are

Table 1: Risk factors distribution among controls and patients

\begin{tabular}{|c|c|c|c|c|c|c|}
\hline & Group I & Group /I & Group III & Group IV & Group V & \\
\hline Variables & $\begin{array}{l}\text { Controls } \\
\mathrm{n}=135\end{array}$ & $\begin{array}{l}\text { NCCP } \\
\mathrm{n}=135\end{array}$ & $\begin{array}{l}U A \\
\mathrm{n}=135\end{array}$ & $\begin{array}{l}\text { NSTEMI } \\
\mathrm{n}=135\end{array}$ & $\begin{array}{l}\text { STEMI } \\
\mathrm{n}=135\end{array}$ & $\begin{array}{l}\text { Significance } \\
\text { (control vs other groups) }\end{array}$ \\
\hline Diabetes mellitus & $21 \%$ & $31 \%$ & $54 \%$ & $58 \%$ & $51 \%$ & S (Group II, III, IV and V) \\
\hline Hypertension & $22 \%$ & $22 \%$ & $57 \%$ & $58 \%$ & $82 \%$ & S (Group II, III, IV and V) \\
\hline Family history of CAD & $0.6 \%$ & $11 \%$ & $32 \%$ & $20 \%$ & $82 \%$ & S (Group II, III, IV and V) \\
\hline Smoking & $16 \%$ & $31 \%$ & $22 \%$ & $30 \%$ & $72 \%$ & S (Group II, III, IV and V) \\
\hline Food habits (non-veg) & $63 \%$ & $73 \%$ & $68 \%$ & $57 \%$ & $79 \%$ & S (Group II, III, IV and V) \\
\hline
\end{tabular}

Note: Chi-square analyses were done,

$p$ value were considered significant at $0.05 \%$

Table 2: Routine parameters distribution among controls and patient

\begin{tabular}{|c|c|c|c|c|c|c|}
\hline Variables & $\begin{array}{l}\text { Group I } \\
\text { Controls } \\
n=135\end{array}$ & $\begin{array}{l}\text { Group /I } \\
N C C P \\
N=135\end{array}$ & $\begin{array}{l}\text { Group III } \\
\text { UA } \\
N=135\end{array}$ & $\begin{array}{l}\text { Group IV } \\
\text { NSTEMI } \\
N=135\end{array}$ & $\begin{array}{l}\text { Group V } \\
\text { STEMI } \\
N=135\end{array}$ & $\begin{array}{l}\text { Significance } \\
\text { (controlvs other } \\
\text { groups) }\end{array}$ \\
\hline $\mathrm{BMI}$ & $25.96 \pm 3.97$ & $26.42 \pm 3.10$ & $27.41 \pm 3.62$ & $25.76 \pm 3.29$ & $27.14 \pm 5.19$ & NS \\
\hline Serum glucose (mg/dL) & $117.22 \pm 38.17$ & $143.00 \pm 48.35$ & $179.39 \pm 89.98$ & $181.64 \pm 74.93$ & $193.13 \pm 91.96$ & $\begin{array}{l}\text { S (Group II, III, IV } \\
\text { and V) }\end{array}$ \\
\hline Serum urea $(\mathrm{mg} / \mathrm{dL})$ & $26.71 \pm 4.83$ & $25.24 \pm 4.49$ & $26.46 \pm 4.34$ & $27.33 \pm 5.17$ & $27.48 \pm 4.47$ & NS \\
\hline Serum creatinine $(\mathrm{mg} / \mathrm{dL})$ & $0.84 \pm 0.13$ & $0.80 \pm 0.12$ & $0.79 \pm 0.10$ & $0.84 \pm 0.11$ & $0.84 \pm 0.14$ & S (Group III) \\
\hline Serum total protein $(\mathrm{mg} / \mathrm{dL})$ & $6.03 \pm 0.84$ & $5.96 \pm 1.00$ & $5.98 \pm 0.83$ & $6.15 \pm 0.86$ & $5.99 \pm 0.74$ & NS \\
\hline Total cholesterol (mg/dL) & $194.79 \pm 32.87$ & $136.08 \pm 39.63$ & $183.59 \pm 45.09$ & $192.77 \pm 44.03$ & $201.52 \pm 42.43$ & S (Group II) \\
\hline LDL (mg/dL) & $91.39 \pm 29.52$ & $110.33 \pm 28.94$ & $133.46 \pm 42.14$ & $124.19 \pm 34.66$ & $131.55 \pm 35.95$ & $\begin{array}{l}\text { S (Group II, III, IV } \\
\text { and V) }\end{array}$ \\
\hline $\mathrm{HDL}(\mathrm{mg} / \mathrm{dL})$ & $45.17 \pm 8.04$ & $38.61 \pm 6.38$ & $37.40 \pm 3.70$ & $36.78 \pm 4.10$ & $38.73 \pm 5.13$ & $\begin{array}{l}\text { S (Group II, III, IV } \\
\text { and V) }\end{array}$ \\
\hline Triglycerides (mg/dL) & $136.08 \pm 39.63$ & $146.83 \pm 45.56$ & $158.76 \pm 58.13$ & $137.19 \pm 51.03$ & $166.51 \pm 45.58$ & S (Group III and V) \\
\hline
\end{tabular}

Note: ANOVA analyses were done; S, Significant; NS, Nonsignificant $p$ values were considered significant at $0.05 \%$

Table 3: Comparison of standard biomarkers (troponin I and CK-MB) with serum and salivary neopterin

\begin{tabular}{lllllll}
\hline & Group I & Group II & Group III & Group IV & Group V & Significance \\
\cline { 2 - 7 } Parameter & Controls & NCCP & UA & NSTEMI & STEMI & $\begin{array}{l}\text { (control vs other } \\
\text { groups) }\end{array}$ \\
\hline Troponin I (ng/mL) & $0.04 \pm 0.211$ & $0.10 \pm 0.54$ & $0.08 \pm 0.19$ & $2.98 \pm 6.70$ & $6.20 \pm 7.32$ & $\mathrm{~S}(\mathrm{Group} \mathrm{IV} \mathrm{and} \mathrm{V)}$ \\
CK-MB (U/L) & $21.66 \pm 10.7$ & $21.42 \pm 10.4$ & $28.39 \pm 1.7$ & $60.91 \pm 76.1$ & $84.63 \pm 79.5$ & $\mathrm{~S}(\mathrm{Group} \mathrm{IV} \mathrm{and} \mathrm{V)}$ \\
Neopterin serum (nmol/L) & $6.88 \pm 1.4$ & $7.35 \pm 1.4$ & $9.44 \pm 2.3$ & $9.78 \pm 1.9$ & $10.82 \pm 1.9$ & $\mathrm{~S}(\mathrm{Group} \mathrm{III,} \mathrm{IV} \mathrm{and} \mathrm{V)}$ \\
Neopterin saliva (nmol/L) & $3.36 \pm 0.73$ & $3.61 \pm 0.73$ & $19.40 \pm 3.53$ & $18.68 \pm 3.13$ & $20.99 \pm 3.48$ & $\mathrm{~S}$ (Group III, IV and V) \\
\hline
\end{tabular}

Note: ANOVA analysis were done; S, Significant; NS, Nonsignificant

$p$ value were considered significant at $0.05 \%$ 
Table 4: ROC curve of biomarkers

\begin{tabular}{lllll}
\hline & & \multicolumn{2}{c}{ Area under the curve } \\
Biomarker & Sensitivity (\%) & Specificity (\%) & (AUC) & Cut off values \\
\hline Troponin I (ng/mL) & 52.84 & 95.56 & 0.771 & 0.02 \\
CK-MB (U/L) & 56.30 & 88.15 & 0.745 & 25 \\
Neopterin serum (nmol/L) & 82.72 & 92.96 & 0.885 & 8.8 \\
Neopterin saliva (nmol/L) & 84.61 & 91.62 & 0.891 & 5.6 \\
\hline
\end{tabular}

under curve show it as a good biomarker. Whereas the established biomarkers like troponin-I, CK-MB have shown significant rise only in STEMI and NSTEMI groups and area under the curve is high. Serum and salivary neopterin have noted more AUC when compared with established biomarkers like troponin-I and CK-MB, which indicates, neopterin to be more sensitive biomarker than troponin-I and CK-MB and it is proven to be a biomarker even for UA. Neopterin being a marker of macrophage activation predicts adverse cardiovascular events in patients with $\mathrm{ACS} .{ }^{7}$ Our previous study, the serum neopterin levels have shown good results in the clinical management of patients with ACS. ${ }^{12}$ So, we attempted estimating salivary neopterin levels and compared the same with serum neopterin levels to establish it in a simple noninvasive procedure.

Although studies carried out on salivary neopterin have been reported in some other context, but none reported the same on patients with ACS. Katoh et al., were the first to estimate salivary neopterin to compare the biopterin and neopterin levels. ${ }^{13}$ Reibnegger et al., estimated salivary neopterin in HIV patients, ${ }^{14}$ Ledjeff et al., in colon dialysate ${ }^{15}$ and Sfriso et al., in Sjogren's syndrome etc. ${ }^{16}$ Biopterin and neopterin and other related pteridines found in human saliva, seem to originate from metabolites in the salivary glands. Saliva contains some components transferred from serum and is a body fluid more easily collected than serum and CSF. ${ }^{17}$ But the studies so far conducted on saliva neopterin did not have a clear picture of neopterin origin in saliva, whether it was due to local production or was a reflection of the concentrations of neopterin in the serum. ${ }^{14}$

Neopterin is produced primarily in monocyte/macrophage and related cells by stimulation with interferons, especially INF- $\gamma$ and TNF-a. ${ }^{17}$ Meisel et al., proposed the mechanism of monocyte activation during the acute phase of $\mathrm{MI}$, where the release of cardiac antigens from the necrotic myocytes activates the $T$ cell to generate cytokines, such as INF- $\gamma$, IL-3, and granulocyte-monocyte colony stimulating factor (GM-CSF). These cytokines cause leukocyte activation which further induces synthesis and release of GM-CSF and IL- 6 by fibroblasts and endothelial cells, along with augmentation of monocyte activation. ${ }^{18}$ Hence, we hypothesize, neopterin as a product of monocyte/macrophage activation in ACS can be due to the acute phasic response wherein the salivary neopterin may be due to the reflection of the concentration of serum neopterin levels along with the neopterin metabolism in the salivary glands.

\section{Conclusion}

Biochemical estimation makes an important role for clinicians to make decisions in treating patients in the emergency unit to rule out AMI and also to determine the thrombolytic therapy. Neopterin being highly sensitive and specific than Troponin and CK-MB can be a surrogate marker of ACS. Salivary neopterin which is cost effective can be easily estimated by noninvasive procedure and can replace routinely serum estimations, which requires about 30 min as time around time.

\section{ACKNOWLedGMENTS}

We thank our Nursing coordinator, Gheetha Gabrial, Nursing supervisor, T Kamatchi for their support in the sample collection, and doctors of FLL clinically managing patients for sample collection. We would like to thank the Indian Council of Medical Research for funding the project.

\section{RefERENCES}

1. Kolansky DM. Acute Coronary Syndromes: Morbidity, Mortality, and Pharmacoeconomic Burden. Am J Manag Care. 2009;15:36-41.

2. Fox KAA, Cokkinos DV, Deckers J, et al. The ENACT study: a panEuropean survey of acute coronary syndromes. European Heart Journal 2000;21:1440-1449.

3. Becker RC. The investigation of biomarkers in cardiovascular disease: time for a coordinated, international effort. European Heart Journal 2005;26:421-422.

4. Christenson RH, Duh SH, Sanhai WR, et al. Characteristics of an Albumin Cobalt Binding Test for Assessment of Acute Coronary Syndrome Patients: A Multicenter Study. Clinical Chemistry 2001;47(3):464-470.

5. Kaski JC, Sanchez LC, Fernandez-Berges DJ, et al. Elevated serum neopterin levels and adverse cardiac events at 6 months follow-up in Mediterranean patients with non-ST-segment elevation acute coronary syndrome. Atherosclerosis 2008;201: 176-183.

6. XG Moll, Coccolo F, Cole D, et al. Serum neopterin and complex stenosis morphology in patients with unstable angina. J Am Coll Cardiol 2000;35:956-962.

7. Avanzas P, Espliguero RA, Quiles J, et al. Elevated serum neopterin predicts future adverse cardiac events in patients with chronic stable angina pectoris. Eur H Jou 2005;26:457-463.

8. Prakova G, Gidikova P, Slavov E, et al. The potential role of neopterin as a biomarker for silicosis. Trakia Journal of Sciences 2005;3(4): 37-41.

9. Berdowska A, Korczala KZ. Neopterin measurement in clinical diagnosis. Journal of Clinical Pharmacy and Therapeutics 2001;26: 319-329.

10. Shubhangi KP, Rajani GT, Aruna AJ. Neopterin: Biomarker of cell-mediated immunity and potent usage as biomarker in silicosis and other occupational diseases. Indian J Occup Environ Med 2008;12(3):107-111.

11. Carru C, Zinellu A, Sotgia S, et al. A new HPLC method for serum neopterin measurement and relationships with plasma thiols levels in healthy subjects. Biomed Chromatogr 2004;18:360-366.

12. Gurumurthy P, Borra SK, Yeruva RKR, et al. Estimation of serum neopterin in patients with acute coronary syndrome. Asian Cardiovascular \& Thoracic Annals 2013;21(4):426-431.

13. Katoh $S$, Sueoka T, Matsuura S, et al. Biopterin and Neopterin in human saliva. Life Sciences 1989;45:2561-2568.

14. Reibnegger G, Fuchs D, Zangerle R, et al. Increased Neopterin Concentration In Saliva of Patients with H1V-1Infection. Clin Chem 1990;36:1379-1380.

15. Ledjeff E, Artner DE, Witasek A, et al. Neopterin Concentrations in Colon Dialysate. Pteridines 2001;12:155-160.

16. Sfriso $P$, Ostuni $P$, Botsios $C$, et al. Serum and salivary neopterin and interferon-gamma in primary Sjogren's syndrome. Correlation with clinical, laboratory and histopathologic features. Scand J Rheumatol 2003;32(2):74-78. 
17. Lars H, Paola C, Magnus G, et al. Cerebrospinal fluid neopterin: an informative biomarker of central nervous system immune activation in HIV-1 infection. AIDS Research and Therapy 2010;7(15): $1-12$.
18. Meisel SR, Shapiro H, Radnay J, et al. Increased expression of neutrophil and monocyte adhesion molecules LFA-1 and Mac-1 and Their ligand ICAM-1 and VLA-4 throughout the acute phase of Myocardial Infarction. J Am Coll Cardiol 1998;31:120-125. 